\title{
Diverse Issues Facing the Business Management Education: A Conceptual Journey
}

\author{
Mohammad Ayub Khan
}

\begin{abstract}
This paper studies of how to construct an integrative-holistic system of education encompassing major diverse issues concerning the modern education of business management. Furthermore, this paper provides a theoretical-conceptual framework which could be used by all stakeholders in educational institutions in order to integrate successfully all those diverse elements affecting the quality and design of the business management education.
\end{abstract}

Index Terms-Business education, educational leadership, graduate competencies, market value of graduates, pedagogy.

\section{INTRODUCTION}

The current business education faces a number of challenges including criticisms from different circles for it being too much market-oriented, the need for customization because of broadening of the business discipline in sub-functional areas (i.e., marketing, accounting, finance and management), faculty shortage, limited attention to applied research, increasing demand for internationalization of curriculum, the increasing dependency of business organizations on information and communication technologies led to the skills gap between what is required in the industry and what is developed and resource limitations [1], [2]. Other contemporary issues such as rankings and accreditations of diverse nature and at different levels have made educational institutions to focus on administrative issue, procedures, indicators and documentation etc. rather than concentrating on educating the future graduates [3]. The current and potential challenges also include the effects of globalization on business education, introducing softer skills into the curriculum while maintaining basic elements of hard skills (analysis, concepts, specialized knowledge), financial issues, governance structure of schools and building reputation and goodwill [4]. Additionally, rapidly changing preferences of various stakeholders (i.e., students, employers, governments, and society), increasing demand for joint studies or double degree/major programs, and the need for multidimensional capabilities and attitudes combined with cognitive acquisition of knowledge are also confronting the business education [5]. In response to various stakeholders' complaints that business schools do not provide students with a comprehensive understanding of the current dynamic organizational system and culture, business schools need to work on transformative learning while integrating discipline-specific knowledge into fully understanding the

Manuscript received February 10, 2014; revised April 17, 2014

Ayub Khan Mohammad is with the Tecnológico de Monterrey, Campus Monterrey, Mexico (e-mail: mkhan@itesm.mx). emerging business organization [6], [7]. Then, the question arises of how to build such educational institutions which, while considering all those diverse issues, could be able to provide integrative-transformative educational programs and services to its students?

\section{LITERATURE REVIEW}

Though there other issues facing the business management education ranging from emerging corporate universities, teaching business ethics, online education, free educational programs, and commercialization of education, however, this paper concentrates on core issues for instances, curriculum development, environmental challenges, pedagogical strategies, graduate competencies, educational leadership, strategic alliances and the market value of graduates.

\section{A. Curriculum Development}

The term curriculum is about "All the learning which is planned and guided by the school, whether it is carried out in groups or individually, inside or outside the school [8]. "Curriculum is simply about taking a subject, preparing it for classroom use, and following through so that it makes a lasting impact on students [9]. Curriculum designers should consider objectives, plans as well as methods, materials and assessment procedures. Especially, the general education curriculum should meet the educational needs of most students, including those with disabilities [10]. Educational theorists [8], [11], [12] view curriculum as a broader concept and therefore, is characterized as: a body of knowledge or product; a process; praxis (practice); and a context Furthermore, curriculum should envisage broader goals and objectives of learning of the educational institutions involving social, cultural, political, religious values of a society [13]. Designing and implementing an integrative curriculum is a big step forward in achieving an integrative learning environment for learners.

\section{B. The Environmental Challenges}

The general environment that surrounds educational institutions has seen drastic and novel changes over the last several years. Causes of these changes include the emergence of global market which is more connected and integrated, the economic system which is open and free, the political system which is investment friendly and democratic, and the revolutionary changes in the field of information and communication technologies [14]. Reference [15] identified several emerging challenges that coincide to a greater extent with the challenges of today such as: global competition is increasing; the knowledge age workforce requires critical thinking skills, flexibility and cooperation; and life-long 
learning and second career training. All educational institutions must work toward producing creative, productive and ethical citizens who can and will contribute to society and industry through the generation and use of new knowledge [15]. It is expected that education institutions develop and transfer knowledge and prepare graduates for the real world (the workplace). In response, educational institutions have to make significant adaptations in the educational programs designed for cosmopolitan leaders. By that it means that educational institutions should take timely actions in response to various environmental developments they face and foresee.

\section{Pedagogical Strategies}

The pedagogy encompasses both teaching and learning methods. A variety of teaching and learning methods are available such as: case based learning; collaborative learning; project based learning; problem oriented learning; service based learning; and, research based learning. A course should be designed and taught using any one or combination of these methods. Teachers are to be properly trained to use appropriately these methods in classrooms. The support of pedagogical experts is necessary in designing and training the faculty. Students' orientation is also important in implementing such methods. Other teaching and learning mechanisms such as professional practices (company based internships) and community services (social services) can also add value to the knowledge and experience of students. Complimentary educational programs including extra academic activities (or transversal programs) including sports, music and dance help students build abilities (artistic, discipline, self-confidence) and social networks. Designing multidisciplinary concentrations (or minors) and modalities are helpful in allowing students to specialize in their area of interest (i.e., research, innovation, consulting, entrepreneurship and social development leadership). Furthermore, pedagogy can be well supplemented by sending students abroad to any foreign country of their choosing, for a period of one semester or at least for a summer or more, allowing them to learn from living and study in an international environment. International exposure allows students to learn new cultures, meet people from different cultural backgrounds, do networking and be open-minded. These are critical success skills university graduates are expected to and should possess in order to function successfully in the emerging global market-workplace. In short, pedagogy must be dynamic, diverse, challenging and interesting. It is also important that students must be at the center of the education policies and programs. Therefore, students' learning styles (active versus passive for example) and teaching styles (student versus teacher centered) must be taken into considerations in designing pedagogical strategies.

\section{Graduate Competencies}

The term competency refers to knowledge, skill and attitude that enable one to effectively perform activities of a given occupation

or function to the standard expected in employment [16]. Competency is the combination of skills, abilities and knowledge needed to perform a specific task [17]. In business and professional life, competencies are used for employee selection, the basis for compensation, performance measurement, training needs assessment, training outcomes assessment and strategic planning. It is believed that having knowledge alone is not sufficient in today's society; students need to adapt to change and to apply their knowledge to solving problems [18]. Four common competencies are found in the existing literature: managing self; communicating; managing people and tasks; and, managing innovation and change [18]. Other competencies include: critical thinking, interpersonal skills and computer skills. Overall, educational purpose should be to develop professional behaviors in learners which may include time management skills, making ethical decisions, participating in professional organizations, appropriate professional appearance, and appropriate meeting behaviors [19]. Common competencies important for the business graduates to have are: ethical reasoning, language and communications abilities, problem-solving skills and preparation for lifelong learning [20].Other job related and technical skills are production and operations management, human resources management and strategic management [21]. Emerging graduate competences such as design mind, creative thinking, innovative thinking, multidisciplinary thinking, mental mapping and projective thinking are added to the list of competencies described above. The challenge for the educational institution therefore, is to articulate integrative educational programs that can and will ensure graduates to possess such multi-dimensional competencies once they graduate.

\section{E. Education Institutional Leadership}

A strong and dynamic leadership is the need of the hour for all educational institutions, especially, for institutions of higher education.Researchers [22], [23] are of the view thateducation leaders need to articulate a vision and create the structure for that vision to come to fruition, not just in words but also in actions and they should be role models for students, faculty and others. The roles of educational leaders include coaching, teaching, counseling, facilitating, directing and sometimes parenting [22], [23]. As an educational leader at any level (i.e., from a course coordinator to the provost to the rector), one must be willing to serve and to subordinate oneself to the vision and best interests of the organization. In a learning organization, leaders are designers, stewards and teachers. They are responsible for building organizations where people continually expand their capabilities to understand complexity, clarify vision and improve shared mental models [23]. In summary, educational institutions, regardless of their size (big or small), types (private or public) and nature of educational programs (business, medicine, engineering, social sciences etc.), require leadership which is not traditional and theoretical, rather which should be dynamic, pragmatic, participative, strategic, and most importantly future oriented, socially inclusive and keep high ethical standards. These leaders in addition to the understanding of academic dynamic of the institution should also possess business skills, cognitive skills, interpersonal skills, personal values and strategic values [24].

\section{F. Strategic Alliances}

Strategic alliances are different types of inter-schools or 
inter -universities cooperation in order to share knowledge, experiences, faculty resources and students amongst others. Strategic alliances are also about universities having collaborative programs with local and international organizations of businesses and social services in order to develop joint projects (i.e., product, service and patent) development. Therefore, strategic alliances in the academic sector are classified as professional and academic alliances. Since the business education is becoming a global need and demand, its globalization is faster in relative terms than other disciplines [25] and thus creating the need for strategic alliances. This is for several reasons [26]: the tough competition combined with falling demand at home for business education has forced business schools in Europe and North America to go abroad; expanding business education abroad is relatively easier when compared to natural, physical and applied sciences; business schools do not need huge investment in physical plant, labs and equipment and faculty development; the demand for business education has increased sharply since newly and emerging democratic-market oriented nations opened their markets including education sector and especially higher education sector for private investments thus encouraging foreign investments in the sector; because of the globalization of all aspects of life including products, services, people, and cultures, educational institutions have no other options except to prepare their graduates as citizen of the world. It is also a common understanding that the national competitiveness depends largely on global knowledge therefore, internationalization strategy by virtue of strategic alliances with other quality educational institutions can better serve the need of improving national educational system. Business schools should develop new strategies to increase their resources and globalize their programs to remain relevant and competitive. Multidimensional strategic and operational collaborations with different institutions offering complementary programs and resources including corporate universities and knowledge cities for example, will help academic institutions to be innovative and proactive in designing and delivering its educational programs.

\section{G. The Market Value of Graduates}

Another critical factor facing the business education is the market value of the graduates composed of economic (quality of life), financial (salaries and other related benefits) and social values (social status). Education does not necessarily mean earning big salaries, holding high profile jobs in the industry or being known for having a business degree per se. But most importantly and ideally, so to say, having a degree (graduate or postgraduate) should be valued considering the role of education and learning in the formation of oneself hence, in becoming an educated, civilized and social contributor. Labor market studies indicate increasingly competitive environment for the job seekers in spite of the fact that industries have grown and are growing in different dimensions creating demands for university graduates. Reasons amongst other are increased number of business schools, rising enrollment and graduation, professional development centers, corporate universities, international mobility of qualified professional from developing countries to developed countries. Generally, the demand for business graduates depends on the overall economic growth, the growth of industries that are graduate-intensive, changes in occupational requirements and standards, changing complexity of work within specific occupations, the number of graduates who leave the labor force. Business degrees are widely accepted qualifications in business management and expected to help enhanced managerial success [27], improved job opportunities, improve earnings and enhanced career progress [28], [29]. Other researchers in the field are of the view that advance business education should enlarge both extrinsic career outcomes such as wage rate, promotions and organizational success and intrinsic career outcomes such as confidence, enhanced interpersonal skills and future mobility opportunities [30], [31].

\section{AN INTEGRATIVE APPROACH TO BUSINESS EDUCATION}

In order to face successfully and effectively those diverse changes and challenges described above, business schools have no options other than to build an integrative approach to managing the education system and educating the future graduates, as demonstrated in Fig. 1. As it is repeatedly underlined in academic debates on business education that modern education should build integrative thinking in students so that they will be able to work successfully in the work environment in which multidisciplinary thinking and decision making is crucial. Integrative thinking is a source of innovative and critical thinking. Remaining competitive and relevant as an academic institution demands from academic institutions surplus resources (financial, human and technological) and interest-based academic programs [32].

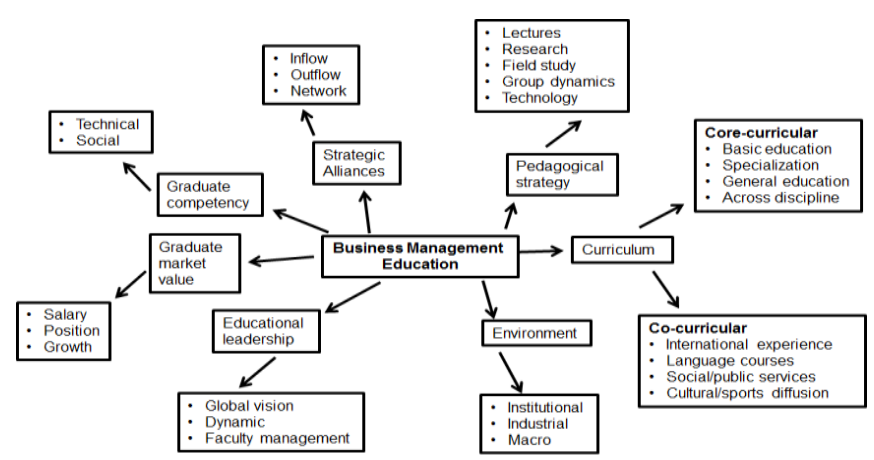

Fig. 1. An integrative approach to business education.

An integrative approach to education involves faculty, students, and the business community. The business community prefers employees who are team players, understand organizational interactions and make decisions that benefit the entire company. The integrative approach of education is also considered as transformational education which goes beyond simply teaching and training the graduates. The integrative learning is about connecting the classroom knowledge to the real world situations and bringing together two forms of knowledge (disciplinary and professional). Integrative thinking is about learning the deeper, underlying meaning of a discipline, making connections across courses and subjects and applying different intellectual perspectives. Integrative thinking is also about creative thinking [33]. Therefore, an integrative approach to education is in demand in the business world and business graduates are expected to clearly demonstrate ability 
to integrate and apply knowledge from a variety of disciplines and to show mastery of discipline-specific knowledge [34].

\section{CONCLUSION, IMPLICATIONS, RECOMMENDATIONS}

This study brings together interesting ideas on developing comprehensive educational programs in order to meet the demands of individuals, business organizations and the society at large. It also lays down a theoretical foundation for future studies on the issue of designing and delivering an integrative education in the field of business management. An integrative education is about connecting learning experiences beginning from early childhood and continues throughout life. An integrative education is about blending knowledge and skills from different disciplinary areas; putting knowledge in to practice, considering multiple perspectives to advance collaborative problem solving, adapting the skills learned in one situation to problems encountered in another, reflecting upon connections made over time among academic, co-curricular and pre-professional experiences and across-the-curriculum integration of skills with learning in disciplinary or interdisciplinary settings etc. [35]. Certainly, the demand for higher education in the field of business and management will continue to grow [4] as well as the need for quality and comprehensive business education.Providing integrative educational programs and services is only possible to achieve when educational institutions are able to blend together all those critical elements shown in Fig. 1 in a timely fashion and in an appropriate manner.

It is ideal and rather phenomenal to have an integrative approach to education management but as there are no roses without thorns so there are implications to face in putting intro practice this approach. For instances: the need for changes in curriculum is constant and rapid since the work and social environment is changing and dynamic; there are differences in learning styles of individual students as well as there are differences in the teaching styles of teachers, so finding out the best match between the two is no easy task; the culture of educational institutions is a critical factor, given the fact that some institutions have centralized management systems, especially, in the public sector which tend to be bureaucratic, rigid and less receptive to external influences; establishing consensus among different stakeholders is time-consuming and almost impossible to establish because of differences in interests and objectives; organizational resources including management time, money, institutional support are always limited; and finally, there is a need for dynamic and strategic leadership inorder to make sure that quality education is developed and delivered in a timely fashion.

Therefore, it is suggested that in order to have an integrative approach to develop, implement and evaluate high quality and integrative education, educational institutions should consider: Having a democratic management system and process which make provision for participation of all the role players [36]; academic institutions that globalize successfully, offer innovative and dynamic academic programs, and invest in information and communication technologies, will remain competitive and successful [4]; learning from successful business schools in terms of designing dynamic and innovative programs, building strong alliances, faculty building, internationalization and multicultural environment for its students [5]; issues like image and reputation based on research, rankings, citations, global performance ranking and international accreditations are important for the current and future generation of business schools [37]; business schools are required to show their abilities to conduct research and teaching relevant to the industrial environment (practitioner) and to the funding agencies [38]; the current century is about technological development, demographical changes and knowledge revolution and that is why business schools are expected to play the role of creating, preserving, integrating, transmitting and applying business knowledge [39]; more experiential/active learning and practical ways of learning and teaching as an integral part of the future educational programs and services in order develop and graduate, really globally responsible leaders [5].

\section{LiMITATIONS AND FUTURE STUDIES}

This study is based on the extensive literature review that exists in the field of business and management education. This paper analyzed theoretically the impact of diverse issues that concern the current education institutions and educational programs thus providing a theoretical foundation for rigorous and quantitative studies in the future. Research methodologists appreciate the role of literature review based studies in establishing the need for further research while broadening the horizons of the researcher and preventing the researcher from conducting research that already exists [40]. Literature review helps the researcher and readers to be knowledgeable and understand the research problem better [41]. Reference [42] suggests "That such studies are helpful in establishing theoretical grounds for research, identify gabs in the existing knowledge and weaknesses in previous research, and discover connections or other relations between different research results by comparing various investigations."Given all those good effects of the outcome of this study, this is a descriptive study involving a type of document analysis and secondary research based on textual information. Some researchers question the validity and reliability of recommendations of such studies since the origin of the information needs scrutiny and critical evaluation. Though this study lays a theoretical justification for designing and delivering an integrative education, however, in order to collect information on ground realities (practices and models) it would be useful to involve interested educational institutions through interviews of professors (one-on-one or in focus groups interviews), administrators, policy makers and industry players alike. Case analyses of educational institutions of different types and in different countries can also bring about interesting and illuminating information in this regard.

\section{REFERENCES}

[1] AACSB International,Management Education at Risk (Report of the Management Education Task Force to the AACSB International Board of Directors), St. Louis, MO., 2002. 
[2] D. Bok, Universities in the Marketplace: The Commercialization of Higher Education, Princeton University Press, 2003.

[3] L. Nino, "Literature review of challenges in business education," The Business Review, Cambridge, vol. 16, no. 1, pp. 339-345, 2010.

[4] G. Hawawini, "The future of business schools," The Journal of Management Development, vol. 24, no. 9, pp. 770-782, 2005.

[5] H. Thomas, "Strategic themes and challenges facing business schools,"Journal of Management Development, vol. 26, no. 1, pp. 9 , 2007.

[6] M. Athavale, R. Davis, and M. Myring, "The integrated business curriculum: anexamination of perceptions and practices," Journal of Education for Business, vol. 83, no. 5, pp. 295-301, 2008.

[7] G. Srikanthan and J. Dalrymple,"A synthesis of a quality management model for educationin universities," The International Journal of Educational Management, vol. 18, no. 4/5, pp. 266-279, 2004.

[8] F. Mednick. (2006). Curriculum Theories. [Online]. Available: http://cnx.org/content/m13293/latest/

[9] W. Null. (2011). From Theory to Practice. Rowman \& Littlefield Publishers, Inc.. [Online]. Available: http://daneshnamehicsa.ir/userfiles/file/Resources/Curriculum__From Theory_to_Practice.pdf

[10] K. Njogu, "Conceptualizing the curriculum: towards a renaissance for theory," American International Journal of Contemporary Research, vol. 2, no. 9, 2012.

[11] M. E. González, G. Quesada, J. Mueller, and R. D. Mueller, "International businesscurriculum design: identifying the voice of the customer using QFD," Journal of International Education in Business, vol. 4, no. 1, pp. 6-29, 2011.

[12] H. Taba, "Curriculum development: theory and practice," Brace \& World, New York, NY: Harcourt, 1962.

[13] E. Krull and H. Kurm, "Hilda Taba-a worldwide known educator from estonia: Taba's biography, ideas, and impact on estonian education," Retrospectiven in SachenBildung, no. 17, 1996.

[14] P. Hallinger and K. Snidvongs, "Educational management administration \& leadership: educating leaders: is there anything to learn from business management?" SAGE Publications, vol. 36, no. 1, pp. 9-31, 2008 .

[15] W. A. Sibley, University Management 2010: Challenging Choices and Difficult Decisions, New Forums Press Inc., 1998.

[16] International Board of Standards for Training and Performance Instruction, 2005.

[17] The National Center for Education Statistics (NCES) of the U.S Department of Education, 2002.

[18] E. Evers, J. Rush, and I. Berdrow, The bases of competence, San Francisco: Jossey-Bass, 1998

[19] A. Hall, "Teaching professional behaviors: differences in the perceptions of faculty, students, and employers," Journal of Business Ethics, vol. 63, pp. 407-415, 2006.

[20] AACSB International. (2012). Eligibility Procedures and Accreditation Standards for Business Accreditation. [Online]. Available: http://www.aacsb.edu.

[21] F. R. David and F. R. David, "Comparing management curricula with management practice," SAM Advanced Management Journal, vol. 76 , vol. 3, pp. 48-55, 2011.

[22] J. Pfeffer. (2009). Leadership Development in Business Schools: An Agenda for Change. Stanford University Graduate School of Business Research Paper. [Online]. Available: http://ssrn.com/abstract=1352622.

[23] P. M. Quickand A. H. Normore, "Moral leadership in the $21^{\text {st }}$ century: everyone is watching-especially the students," The Educational Forum, West Lafayette, vol. 68, no. 4, pp. 336, 2004.

[24] V. Kalargyrou, A. Pescosolido, and E. A. Kalargiros, "Leadership skills in management education," Academy of Educational Leadership Journal, vol. 16, no. 4, pp. 39-63.

[25] H. Moon, The Globalization of Professional Management Education, 1881-2000: It's Rise, Expansion, and Implications, Stanford University, 2002.
[26] A. Ahmad and C. P. Rao, "The university as a multinational corporation," Journal of International Business Education, vol. 6, pp. $119-138,2011$

[27] Y. Baruch and M. Peiperl, "The impact of an mba on graduate careers," Human Resource Management Journal, vol. 10, no. 2, pp. 69-90, 2000

[28] C. A. Carnall, MBA Futures, Basingstoke: MacMillan, 1992.

[29] B. Luker and T. L. Powers, "Factors influencing pursuit of the mba degree: a student and employer perspective," Journal of Marketing for Higher Education, vol. 2, no. 2, 1989.

[30] R. Simpson, J. Sturges, A. Woods, and Y. Altman, "Gender, age, and the mba: an analysis ofextrinsic and intrinsic career benefits," Journal of Management Education, vol. 29, no. 2, pp. 218-247, 1989.

[31] M. Carlin, "The impact of the mba on career outcomes: an analysis of male and female graduates," Capella University, ProQuest, UMI Dissertations Publishing, 2011

[32] E. Cornuel, "Challenges facing business schools in the future," The Journal of Management Development, vol. 26, no. 1, pp. 87-926, 2007.

[33] D. Berrett. (2013). Double Majors Produce Dynamic Thinkers, Study Finds. The Chronicle of Higher Education. [Online]. Available: http://chronicle.com/article/Double-Majors-Produce-Dynamic/137917

[34] J. McKay-Nesbitt, E. Yobaccio, A. Wicks, and K. K. Asare, "Integrative business education focused on the environment: a description of the sophomore scholars program, its effects on academic performance, and the regulatory focus of its participants," Journal of Higher Education Theory and Practice, vol. 12, no. 6, pp. 100-119, 2012.

[35] R. Miller, Integrative Learning and Assessment, pp. 11-14, 2005.

[36] F. M. Hayward, Internationalization of US Higher Education: Preliminary Status Report, Washington, DC: A.C.O. Education, 2000.

[37] D. C. Wilson and T. Howard, "The legitimacy of the business of business schools: what's the future?" The Journal of Management Development, vol. 31, no. 4, pp. 368-376, 2012

[38] H. Thomas and A. D. Wilson, "Physics envy, cognitive legitimacy or practical relevance: dilemas in the evolution of management research in the UK," British Journal of Management, vol. 22, no. 3, pp. 443-456, 2011.

[39] A. Mbaatyo, "Business cohesion: Managing schools of business in the age of knowledge," Advanced Management Journal, vol. 66, no. 2, pp. 29-38, 2001.

[40] J. Aitchison, MIS Thesis, University of Natal, 1998, Pietermaritzburg.

[41] C. Bless and C. Higson-Smith, Fundamentals of Social Research: An African Perspective, 3rd Edition, Cap Town: Juta. 2000

[42] P. Leedy, Practical Research: Planning and Design, 4rth Edition, New York: MacMillan. 1989

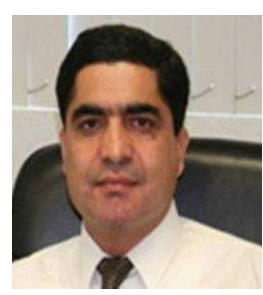

Mohammad Ayub Khan was born in Chitral, Pakistan and studied MBA at Quaid-e-Azam College of Commerce, University of Peshawar, Pakistan in 1990. Later on, he studied international MBA from Glasgow University, Scotland, UK in 1994. While in Mexico, he completed his PhD in business administration, from Trident University International, California, USA (2005). Dr. Ayub has remained the director of the International Business Department at Tecnologico de Monterrey, campus Monterrey, Mexico. Currently, he is serving as an associate professor of international business and the director of the University Honors Program at the same university. He research interest includes business management education, honors education, negotiation, cross cultural consumer behavior, stakeholder analysis; the role of information technology in business and business education. He has co-authored a book titled "The Basics of International Negotiation", ISBN 978-3-639-31584-4. www.vdm-vsg.de. Currently, he is involved in co-authoring a book on "Diverse Contemporary Issues Facing the Business Management Education" to be published by IGI publication. 